\title{
GARANTÍA DE LA POLÍTICA PENAL COMO LÍMITE AL DECISIONISMO PENAL*
}

María Belén Bonilla Albán**

Resumen: El ensayo explica cómo la inclusión de la garantía de la política pública en la Constitución de 2008 de Ecuador, que forma parte del Estado constitucional, de derecho y justicia o "Estado garantista", puede convertirse en un límite sustancial para el decisionismo penal, que suele estar detrás de la política penal en América Latina. De esta manera, la función de este tipo de garantía es eliminar el enorme espacio de discrecionalidad en la gestión de la más sensible de las políticas del Estado moderno: la política penal. Sin embargo, la garantía de la política pública no es clara en determinar los límites del poder punitivo, por lo cual, en este trabajo se busca explorar algunos de los estándares internacionales de Derechos Humanos que le den contenido.

Palabras clave: Garantismo penal; Política penal, Estado constitucional; Derechos Humanos; Neoconstitucionalismo; Garantías constitucionales.

* Fecha de recepción: 31 de agosto de 2015. Fecha de modificación: 5 de marzo de 2016. Fecha de aceptación: 24 de junio de 2016. Para citar el articulo: María BelÉn Bonilla Albán. "Garantía de la política penal como límite al decisionismo penal”, en Revista Derecho Penal y Criminología, Vol. 38, n. ${ }^{\circ}$ 102, enero-junio de 2016. Bogotá: Universidad Externado de Colombia, pp. 121-140. DOI: http://dx.doi.org/10.18601/ 01210483.v37n102.07

** Abogada de los Tribunales de la República del Ecuador por la Universidad Regional Autónoma de los Andes de Ecuador, especialista en Derecho penal en ciencias criminológicas de la Universidad Externado de Colombia, especialista en Derecho constitucional por la Universidad Andina Simón Bolívar sede Ecuador. San Francisco de Quito, Ecuador. E-mail: belen_bonillaalban@ @otmail.com. 


\title{
GUARANTEE OF CRIMINAL POLICY AS LIMITED TO CRIMINAL DECISIONISM
}

\begin{abstract}
The essay explains how the inclusion of the security of public policy in the 2008 Constitution of Ecuador as part of the constitutional state of law and justice or "guarantor state" can become a substantial limit for criminal decisionism, which is usually behind the penal policy in Latin America. Thus, the function of this collateral is to eliminate the huge space of discretion in the management of the most sensitive policy of modern state penal policy. However, the guarantee of public policy is not clear in determining the limits of punitive power; therefore, this paper seeks to explore some of the international human rights.
\end{abstract}

Keywords: Penal Guarantees; Penal Policy; Constitutional State; Human Rights; Neo-Constitutionalism; Constitutional Guarantees.

\section{INTRODUCCIÓN}

En Latinoamérica, durante la primera década del siglo XXI, acontecieron varios fenómenos políticos que han propiciado la emergencia de reformas políticas en toda la región. Gran parte de las reformas han sido canalizadas, como es tradicional en nuestros países, mediante procesos constituyentes y textos constitucionales. Ecuador no es la excepción de esta tendencia histórica.

Sin embargo, nuestro proceso político tiene rasgos comunes y propios. Los propios se refieren a la tendencia a la apertura democrática que va desde el referéndum para elegir entre textos constitucionales alternativos (1979) hasta el último proceso constituyente, en el cual los ecuatorianos decidimos por consulta popular la convocatoria a la Asamblea Constituyente, la votación por el estatuto mínimo de funcionamiento de aquella, la elección de los constituyentes, la participación activa en el proceso constituyente, y un referéndum para decidir el texto constitucional final. Por su parte, nuestro proceso está emparentado con la corriente social-constitucional que comenzó con la Constitución de Venezuela (1999) y culminó con la de Bolivia (2009).

Al mismo tiempo, nuestro proceso fue distinto, en la medida en que se basó en el ideal de la democracia participativa, el papel activo del Estado y la economía social, y no como ocurrió en la Constitución de 1998, que se relacionó con la denominada gobernabilidad, el papel regulador del Estado y la economía de mercado ${ }^{1}$.

Un elemento cohesionador de este proceso ha sido el concepto de Estado constitucional o Estado garantista de derechos que se incluye en el artículo 1 de la Constitución

1 Cfr. Hurtado $(1989,1990$ y 1993. 
de la República del Ecuador de 2008, lo cual significa no solo que la Constitución es la norma suprema del ordenamiento jurídico, sino que, además, el Estado tiene una obligación negativa y positiva de desarrollar los derechos (MELish, 2003, p. 171). Esto es un cambio trascendental, puesto que normalmente el clásico modelo de Estado liberal estuvo pensado como obligado solo negativamente, es decir cumplía con la tutela de los derechos al no hacer o dejar de hacer. Por ejemplo, dejar de matar o torturar. Pero la obligación positiva significa que el Estado debe hacer.

En un Estado constitucional, las garantías son los mecanismos para materializar los derechos. Nuestra Constitución estableció así las garantías legislativas y de la política pública junto a las clásicas garantías jurisdiccionales (artículos 84 y 85 de la Constitución de la República del Ecuador) con el fin de maximizar la tutela de derechos. No obstante, no estableció cuáles son los mecanismos concretos para el funcionamiento de las garantías normativas y de la política pública (Organización de Naciones Unidas, 2005).

Me parece importante determinar los estándares que pueden servir para que funcionen las garantías de la política pública. Aquello, en gran medida, es la razón de ser del Estado en la vida cotidiana de las personas y colectivos en un Estado constitucional, de derechos y justicia. Creo que lo más cercano a un sistema viable de estándares lo podemos encontrar en las propuestas que diversas oficinas de la ONU han realizado respecto del enfoque de derecho en varias temáticas de las políticas públicas nacionales ${ }^{2}$.

Al mismo tiempo, la emergencia de este tipo de garantías surge en el mundo como resultado de un fenómeno global de constitucionalización del derecho, particularmente del Derecho penal como disciplina y práctica jurídica, tal como lo manifiesta FERRAJOLI en varias de sus obras (2001, p. 17; 2001a, p. 14). Dentro de este ámbito, en nuestra Constitución, el desarrollo constitucional del debido proceso y las normas específicas de protección penal y de personas privadas de la libertad son un ejemplo de este fenómeno político-jurídico (artículos 75-77 de la Constitución de la República de Ecuador).

No obstante, en este ámbito quedan algunos puntos ciegos donde la constitucionalización no llega aún. Justamente, uno de estos es el de la política penal o criminal. Así, si bien es cierto que las normas del debido proceso, normalmente, están guiadas a los procedimientos penales - pensemos, por ejemplo, en el derecho a la defensa y el principio de legalidad-, el Estado ecuatoriano diluye sus contenidos en un de-

2 Grupo de Evaluación de Naciones Unidas (2011), Oficina del Alto Comisionado de los Derechos Humanos de Naciones Unidas (2006), Oficina del Alto Comisionado de los Derechos Humanos de Naciones Unidas (2008), Organización de Naciones Unidas (2005) Organización de Naciones Unidas para la Educación, la Ciencia y la Cultura (2008), Organización de Naciones Unidas (2005a) y Sexagésimo Período de Sesiones, Asamblea General de la Organización de Naciones Unidas, Resolución 60/251,3-abr-2006. 
cisionismo que va en contra de toda materialidad constitucional. Por esta razón, vemos operativos y redadas que bajo la consigna de "lucha contra la delincuencia" permiten a agentes policiales entrar en el domicilio de las personas que viven en los barrios marginales; la realización de revisiones aleatorias en los colegios para buscar drogas, o la implementación de un sinnúmero de sistemas electrónicos de vigilancia en lugares públicos supuestamente vinculados al cometimiento de delitos (centros de tolerancia, bares y moteles), aun en contra del derecho a la intimidad de la vida privada de las personas.

Pareciera que los resguardos constitucionales del debido proceso penal que están en el texto constitucional no son suficientes para garantizar una política penal constitucionalizada. Por supuesto, esta situación se repite en toda la política pública. Vemos lo que ocurre en la práctica real de los derechos sociales que ha sido ampliamente estudiada por varios académicos en las últimas décadas (ABRAMOVICH, 2007, p. 35 , y ABRAMOVICH y COURTIS, 2009, p. 245). Existe, entonces un hilo común: la debilidad institucional de nuestros Estados y la precariedad de nuestros sistemas de control social. Aquello reviste particular gravedad cuando se trata del poder judicial y del potencialmente desbordado poder punitivo.

De acuerdo con esto, creo que son necesarios otros límites de contención del aparato punitivo, los cuales podemos encontrar en las garantías de la política pública del artículo 85 de la Constitución de la República de Ecuador:

Art. 85.- La formulación, ejecución, evaluación y control de las políticas públicas y servicios públicos que garanticen los derechos reconocidos por la Constitución, se regularán de acuerdo con las siguientes disposiciones:

1. Las políticas públicas y la prestación de bienes y servicios públicos se orientarán a hacer efectivos el buen vivir y todos los derechos, y se formularán a partir del principio de solidaridad.

2. Sin perjuicio de la prevalencia del interés general sobre el interés particular, cuando los efectos de la ejecución de las políticas públicas o prestación de bienes o servicios públicos vulneren o amenacen con vulnerar derechos constitucionales, la política o prestación deberá reformularse o se adoptarán medidas alternativas que concilien los derechos en conflicto.

3. El Estado garantizará la distribución equitativa y solidaria del presupuesto para la ejecución de las políticas públicas y la prestación de bienes y servicios públicos.

En la formulación, ejecución, evaluación y control de las políticas públicas y servicios públicos se garantizará la participación de las personas, comunidades, pueblos y nacionalidades. 
Por supuesto, esta idea está matizada por una visión que puede ser catalogada de institucionalista, por tal razón, insuficiente y posiblemente algo ingenua. Pero, corresponde a un intento por dar racionalidad a la política penal. Aquello quiere decir, además, que la política penal se convierte en una política pública. Esto tiene, a mi criterio, dos ventajas: por una parte, el decisionismo penal del Estado se somete a los controles constitucionales ordinarios, y por la otra, se racionaliza el quehacer penal en su materialidad y no solo en su formalidad.

En consecuencia, tal como ya se dijo, los estándares para poder desarrollar el artículo 85 de la Constitución pueden ayudar a desarrollar una política penal constitucionalizada.

Con estos antecedentes, el propósito de este ensayo es compilar los estándares internacionales de Derechos Humanos que permitan establecer parámetros para guiar, de manera general, la elaboración de la política penal del Estado desde la garantía de la política pública (artículo 85 de la Constitución) en un Estado constitucional, de derechos y justicia. En fin, este trabajo se dividirá en las siguientes partes: (1) estándares internacionales de derechos humanos sobre el enfoque de derechos; (2) propuesta de implementación para la garantía de las políticas públicas en Ecuador; (3) propuesta de implementación para la política penal, y (4) conclusiones.

\section{ESTÁNDARES INTERNACIONALES DE DERECHOS HUMANOS SOBRE EL ENFOQUE DE DERECHOS}

\section{El contexto de los Derechos Humanos y las garantías constitucionales}

Suele marcarse como el inicio de la política de los Derechos Humanos el 10 de diciembre de 1945, fecha en la cual se aprobó la Declaración Universal de los Derechos Humanos. No obstante, se puede decir que lo que hoy denominamos "Derechos Humanos" tuvo importantes raíces anteriores. Creo que los Derechos Humanos son una constante en la Humanidad, pero solo es en la época moderna que se construye una doctrina orgánica respecto de ellos. En esta medida, podemos decir que representan:

... la lucha incesante de los oprimidos contra los opresores, de los débiles contra los fuertes y de los explotados, que siempre han sido la mayoría, contra los grupos de explotadores... (CAMARGO, 1995, p. 3).

Esta teoría tiene una de sus fuentes en las declaraciones inglesas de derechos: la Carta Magna (1215), la Petición de Derechos (1628), Habeas Corpus Act (1679) y The Bill of Rights (1688), y en la doctrina de los Derechos Naturales en Inglaterra, de la mano de Hobbes, quien define el derecho del hombre como "un derecho subjetivo natural consistente en la libertad que posee todo hombre de usar su poder como quiera..." (HEIBNER, 1993, p. 38). 
No obstante, fueron otros pensadores quienes delinearon de manera más clara esta teoría a partir de los derechos naturales, entre los que destacan Hugo Grocio (1583-1645), SAMuel von PufEndorf (1632-1694) y, particularmente, JoHn Locke (1632-1704). Su ideario giró alrededor del estado de la naturaleza donde todos los hombres son iguales, la necesidad del pacto social y la separación de los poderes públicos para poder limitar el poder y garantizar el respeto de los derechos de las personas (VILLEY, citado por HEIBNER, op. cit., 1993, p. 37). Sin embargo, en la época moderna, quien logra sentar las bases teóricas de los actuales derechos humanos es EMMANUEL KANT (1738-1794), quien veía en la limitación de la libertad propia la libertad de los demás, proponiendo un ideal revolucionario incluso hoy: "Un ser humano siempre será un fin y jamás un medio... El ser humano es la medida de todas las cosas" (CAMARGO, op. cit., p. 11).

Justamente, el pensamiento de Locke y con impronta del juez Coke respecto de lo judicial, inspiraron la Declaración de derechos de Virginia del 12 de junio de 1776 (GONZÁLEZ, 1998, p. 51-54), elaborada por MASSON (ídem,p. 11), ${ }^{3}$ denominada The Bill of Rights, y la Declaración de Independencia de los Estados Unidos de América del 4 de julio de 1776, redactada por THOMAS JEFFERSON (ídem, p. 75).

Esta corriente también tuvo eco en Francia con MoNTESQUiEu (1689-1755), quien hacía referencia a la implementación de la democracia representativa en su obra fundamental El espíritu de las leyes y la doctrina de la separación de poderes; y en JACOBO RoussEAU (1712-1778), quien propugnaba un individualismo solo limitado por el denominado contrato social, título de uno de sus libros más famosos y difundidos. Sus ideas tomaron forma material finalmente, con el derrumbe del absolutismo, en la Asamblea Nacional de Francia, el 26 de agosto de 1789, con la aprobación de la Declaración de los Derechos del Hombre y del Ciudadano en el marco de la Revolución Francesa (HEIBNER, op. cit., p. 45) 4

Otro aporte fue el de CARLOS MARX (1818-1883), especialmente, en su ensayo La cuestión judía (1843), pues realiza una crítica en el sentido de que el ideal del Derecho favorece a intereses de clase y el egoísmo de una sociedad burguesa, puesta en escena en el famoso Manifiesto comunista (1848). Esto fundó una línea realista importante en las modernas corrientes críticas de los derechos humanos, puesto que

3 "Que todos los hombres son por naturaleza igualmente libres e independientes y tienen ciertos derechos innatos...".

4 No obstante, inmediatamente, esta gesta revolucionaria tuvo sus detractores, incluso por fuera de las fuerzas realistas que buscaron la restauración monárquica a lo largo de los siglos XVIII y XIX. Este fue el caso del inglés EDMUND BuRKE (1729-1797), en su obra Reflexiones sobre la Revolución Francesa (1790), quien arremete en contra del individualismo de la ideología liberal y los excesos respecto de los acontecimientos posteriores a la Revolución Francesa. Más adelante, JerEmías BenTHAM (1748-1832) cuestiona en su Anarchical Fallacies la existencia de los derechos naturales y califica la Declaración de los Derechos del Hombre y del Ciudadano como "una jerigonza sin sentido...". 
propició la incorporación del fenómeno económico, político y social en los instrumentos y en la práctica de los derechos humanos hoy. En gran medida, los denominados Derechos Económicos, Sociales y Culturales (DESC) y los Derechos Colectivos son de inspiración socialista.

Es decir, el duro cuestionamiento que recibieron estos primeros instrumentos internacionales de Derechos Humanos llevó al planteamiento de los denominados Derechos sociales, lo cual extendió su espectro a lo económico, social y cultural, y se instrumentó en la segunda Declaración de los Derechos del Hombre y del Ciudadano el 24 de junio de 1793 (ídem, p. 48). Posteriormente, esto se incorporó a la Constitución francesa del mismo año -nunca entró en vigencia (GoNZÁLEZ, op. cit., p. 231 $)^{5}$. Así, entre las dos Guerras Mundiales se implementó el Derecho Social en las Constituciones de México (1917) y Weimar (1919), las cuales motivarían luego el Pacto Internacional de Derechos Sociales, Económicos y Culturales (1966) como complemento del Pacto Internacional de Derechos Civiles y Políticos (1966).

Por otra parte, un hito muy importante en la historia de los Derechos Humanos fue, sin duda, la Declaración de los Derechos Humanos de la Mujer y la Ciudadana $(1791)^{6}$, la cual fue obra de OLYMPE DE Gouges (1748-1793), y cuyas ideas de alguna manera inspiraron la obra Defensa de los derechos de la mujer de la escritora inglesa Mary Wollstonecraft publicado en 1792. No obstante, Olympe murió en la guillotina y sus seguidoras feministas de todo el mundo solo lograron tener un instrumento universal para su protección (Convención sobre la eliminación de todas las formas de discriminación contra la mujer) luego de más de 200 años ${ }^{7}$. En todo caso, en la Declaración Universal de 1948, la Comisión especial, a instancias de ELEANOR RoOSEVELT, logró incluir en el texto la frase "seres humanos" y no "hombres" (GONZÁLEZ, op. cit., p. 203).

Posteriormente, luego de la Primera Guerra Mundial (1914-1918), con el fin de garantizar la paz, se crea la Liga de Naciones con el predominio de los países ganadores de esta guerra, sembrando el germen de la siguiente conflagración mundial. El horror y la vergüenza que causó la constatación por la humanidad de la degradación de la

5 El Derecho social también recibió aportes importantes desde la doctrina social de la Iglesia, especialmente, a partir del pensamiento del obispo de Maguncia WILHELm EMmanuel von KeTteLER (1811-1877) y de la encíclica de León XIII, Rerum novarum (1891). Posteriormente, luego del triunfo de la Revolución bolchevique en Rusia, se realizó la Declaración de los derechos del pueblo trabajador y explotado del 3 de enero de 1918, escrita por el mismo LENIN. Declaración que desembocaría en lo posterior en la Conferencia de Derechos Humanos de Helsinki, la cual, según algunos, abrió las puertas para el cambio en los Estados del este de Europa.

6 http://es.wikipedia.org/wiki/Olympe_de_Gouges. Esta declaración comenzaba con la frase: “... Hombre, ¿eres capaz de ser justo? Una mujer te hace esta pregunta...”.

7 Centro de información y documentación de Isis Internacional, http://www.undp.org/rblac/gender/ campaign-spanish/womenshumanrights.htm. 
naturaleza humana lleva a la firma de la precursora Declaración Americana de los Derechos y Deberes del Hombre, aprobada en la Ix Conferencia Interamericana de Bogotá del 2 de mayo de 1948, y a la Declaración Universal de Derechos Humanos, aprobada por la Asamblea General de la Organización de las Naciones Unidas del 10 de diciembre de 1948 (Camargo, op. cit., p. 13) ${ }^{8}$. El cambio cualitativo fue que este nuevo intento no solo tuvo como finalidad asegurar la paz, sino también la defensa de los derechos fundamentales de cualquier ser humano (ídem).

Un elemento central en este nuevo orden mundial fue el establecimiento del principio de responsabilidad de los Derechos Humanos, que había variado de acuerdo con el tipo de normativa y el momento histórico-político mundial. De esta manera, se pudo observar la emergencia de un verdadero sistema de protección internacional de Derechos Humanos, que establece mecanismos jurídicos y políticos para proceder en contra de los Estados que han violado tales derechos, lo cual supuso, en mayor o menor medida, una atenuación del concepto de soberanía de los Estados y la transformación de las personas naturales en sujetos del Derecho internacional.

No obstante, en los instrumentos hasta aquí citados, la responsabilidad del Estado no es únicamente política, sino jurídica. De esta manera, se crea un sistema de tutela supranacional, administrativo-jurisdiccional, en la Convención Europea de Salvaguardia de los Derechos del Hombre y de las Libertades Fundamentales o "Convención de Roma", elaborada por el Consejo de Europa el 4 de noviembre de 1950, completada por la Carta Social Europea de 18 de octubre de 1961 (HeIBner, op. cit., p. 53).

En el caso de nuestro continente, como consecuencia de esta corriente universal y a partir de la denominada "Doctrina Roldós" (propuesta por el expresidente de la República de Ecuador JAIME Roldós AGUILERA) - que criticaba el dramático estado de atentados contra los Derechos Humanos por parte de gobiernos militares en América Latina-, con poca diferencia de tiempo, en América se creó el Sistema Interamericano de Derechos Humanos, inaugurado con la creación de la Comisión Interamericana de Derechos Humanos en la Quinta Reunión de Consulta de Santiago de Chile en 1959, sobre la base de la Declaración de 1948.

Posteriormente, en 1969, en Costa Rica, se celebra la Convención Interamericana de Derechos Humanos o "Pacto de San José", la cual, junto con sus respectivos protocolos, estatutos y reglamentos de la Corte y Comisión, conforma el núcleo duro del Sistema Interamericano (ídem). Un elemento central en la Convención es la amplitud de la jurisdicción, lo cual parece corresponder con la tendencia mundial

8 Se le encargó a la Comisión de Derechos Humanos la misión de redactar la declaración de derechos que no estuvo en la Carta de San Francisco de 1945 que dio origen a la Organización de Naciones Unidas. La Declaración Americana es precursora en la temprana inclusión de los derechos sociales y los deberes de los ciudadanos. 
de extenderla a una jurisdicción universal (MEDINA, 2003, pp. 11-14). Este SIDH reconoce una instancia de denuncia preliminar que es la Comisión, y una de juzgamiento definitivo que es la Corte. El requisito básico es el agotamiento de la vía judicial interna en el país del denunciante. En caso de conflicto sobre la normativa sustantiva aplicable, se reconoce aquella que favorezca la aplicación de los Derechos Humanos y aquellos inherentes a la persona humana, admitiendo, inclusive, lo que se conoce como ius cogens ${ }^{9}$, que serían los derechos establecidos en los instrumentos internacionales (principio de progresividad del artículo 29 de la Convención) (Centro por la Justicia y el Derecho Internacional cejil, 2004, p. 37). Por otro lado, los criterios de interpretación que hacen referencia al principio de integralidad, el denominado corpus iuris del Derecho internacional de los Derechos Humanos, la jurisprudencia de los órganos de justicia de los Estados, la doctrina de los publicistas de todas las naciones, los principios de buena fe y el principio in dubio pro homine (MedinA, op. cit., pp. 2-10).

Por su parte, en el sistema de las Naciones Unidas, existió desde un principio la Comisión de Derechos Humanos, la cual, a su vez, vio dispersada su actuación a través de un sinnúmero de subcomisiones. En la Declaración de Viena de 1993 se crea el Comisario de los Derechos Humanos, cuya misión principal fue coordinar todos estos organismos. Finalmente, la Comisión de Derechos Humanos es sustituida el 3 de abril de 2006 por el Consejo de Derechos Humanos, al cual se dota de mayores competencias, incluso, de receptar denuncias ${ }^{10}$.

Sin embargo, debe decirse que la política de la Guerra Fría impidió que los Estados asumieran los Derechos Humanos como una integridad, por lo cual, por ejemplo, los países de la órbita soviética dieron primacía a los Derechos Económicos, Sociales y Culturales; mientras que, los países del influencia capitalista, privilegiaron a los Derechos Civiles y Políticos. En realidad, los Derechos Humanos fueron un pretexto para la lucha de fondo por imponer un modelo político-económico, lo cual no permitió exigir eficientemente responsabilidad a los Estados. En medio de estas dos posiciones estuvieron algunos países, por ejemplo, los escandinavos y de gran parte de la Europa continental con cierta cercanía al socialismo y al denominado Estado de Bienestar; y, del otro lado, los países latinoamericanos y del sudeste asiático, que tuvieron gran influjo capitalista combinado con un Estado interventor.

A pesar de esto, luego de la caída del Muro de Berlín en 1989, la Conferencia Mundial de los Derechos Humanos de Viena (14-25 de junio de 1993) estableció la integralidad e indivisibilidad de los derechos humanos, de acuerdo con lo cual los

9 Comisión Interamericana de Derechos Humanos, informe 62/02, caso 12.285, Michael Domínguez v. Estados Unidos, 22-oct-2002, párrafo 49.

10 Sexagésimo período de sesiones, Asamblea General de la Organización de Naciones Unidas, Resolución 60/251, 3-abr-2006. 
Estados pueden ser requeridos por la violación de cualquier derecho humano, lo cual supone un viraje hacia el objetivo final: transformar a la persona humana en sujeto de protección del Derecho internacional. Este suceso histórico fortaleció, en un inicio, la protección de los derechos humanos durante las décadas de 1980 y 1990, al punto que muchos académicos pensaron que la época de los derechos había llegado. BoBBio (1997, pp. 165-169), por ejemplo, llamó a este fenómeno la "revolución de los derechos".

Sin embargo, luego del atentado del 11 de septiembre de 2001 a las Torres Gemelas en Estados Unidos, se inició por parte de las potencias centrales una "guerra justa" en contra de varios grupos denominados terroristas, lo cual resucitó el principio de soberanía y debilitó el sistema internacional de derechos humanos, especialmente cuando las potencias centrales iniciaron la invasión de Irak y Afganistán. Al mismo tiempo, varios flagelos transnacionales han puesto en escena la participación de entes por fuera de los Estados, afectando derechos de personas y colectivos en todo el planeta: a) afectación al medioambiente por la explotación de recursos no renovables; b) presiones laborales por el mercado internacional y migración en términos de precariedad laboral; c) la trata y tráfico de personas y tráfico de drogas, y d) el impacto de las políticas de seguridad de los Estados ante estos fenómenos del mundo global (FERRAJOLI, 2001, p. 195).

En gran medida, podemos decir que, en la actualidad, el sistema de Derechos Humanos está en crisis, lo cual puede verse en la polémica en la que se ven inmersos los organismos de defensa de los Derechos Humanos, universales y regionales en todas partes. A pesar de esto, en algunos países se han realizado reformas para fortalecer los sistemas locales de protección. Es el caso de Ecuador, que en la Constitución de 2008 incorpora un sistema fuerte de garantías constitucionales, que tiene que ver no solo con las clásicas garantías jurisdiccionales, sino con la política pública y las normas jurídicas (artículos 84-86 de la Constitución vigente) y, también con la incorporación de un estatuto de derechos de avanzada (derechos colectivos, de personas de atención prioritaria, de la naturaleza, etc.). Aquello llevó a la creación de la Corte Constitucional y a la incorporación de organismos de protección de derechos autónomos (Defensoría del Pueblo y Defensoría Pública) y en todo el Estado (Ministerio de Justicia, Derechos Humanos y Cultos, direcciones de Derechos Humanos, comités y consejos de Derechos Humanos, etc...).

En este contexto, apareció la Constitución de 2008 en Ecuador. El ideal de esta Constitución era garantista, por lo cual no solo se incluyeron las clásicas garantías jurisdiccionales, sino las garantías normativas y de la política pública. Esta tríada de mecanismos se incorporó en el texto constitucional con el fin de materializar los Derechos Humanos, cuyo canal normativo sería la propia Constitución de Ecuador de 2008. Veamos el artículo 85 de la Constitución, en donde se desarrolla la denominada garantía de la política pública: 
Art. 85.- La formulación, ejecución, evaluación y control de las políticas públicas y servicios públicos que garanticen los derechos reconocidos por la Constitución, se regularán de acuerdo con las siguientes disposiciones:

1. Las políticas públicas y la prestación de bienes y servicios públicos se orientarán a hacer efectivos el buen vivir y todos los derechos, y se formularán a partir del principio de solidaridad.

2. Sin perjuicio de la prevalencia del interés general sobre el interés particular, cuando los efectos de la ejecución de las políticas públicas o prestación de bienes o servicios públicos vulneren o amenacen con vulnerar derechos constitucionales, la política o prestación deberá reformularse o se adoptarán medidas alternativas que concilien los derechos en conflicto.

3. El Estado garantizará la distribución equitativa y solidaria del presupuesto para la ejecución de las políticas públicas y la prestación de bienes y servicios públicos.

En la formulación, ejecución, evaluación y control de las políticas públicas y servicios públicos, se garantizará la participación de las personas, comunidades, pueblos y nacionalidades.

\section{Análisis estructural de los estándares para el enfoque de Derechos Humanos}

En el contexto del auge de los Derechos Humanos durante la década de 1990 en todo el planeta, la gran mayoría de Estados en los foros internacionales dirigieron sus esfuerzos al debate sobre la materialización de los instrumentos internacionales de Derechos Humanos (Melish, op. cit., p. 145). Sin embargo, los sistemas políticos habían cambiado desde 1948, cuando se promulgó la Declaración Universal de los Derechos Humanos. Para aquella época, la mayoría de países europeos tenían regímenes parlamentarios y partidos políticos fuertes, es decir, teníamos sistemas profundamente legislativos. Si bien es cierto que algunos países, incluidos los Estados Unidos de América y los latinoamericanos, tenían regímenes presidenciales, unos más fuertes y consolidados que otros, gran parte de la política pública pasaba por la elaboración y promulgación de leyes, en detrimento de la jurisprudencia y de las políticas públicas como fuentes de derecho o como norma de referencia social (LÓPEZ, 2001, pp. 11-28).

Paralelamente, debemos entender que en los ordenamientos nacionales se han incorporado mecanismos de garantía, a nivel constitucional y legal, así como de políticas públicas y jurisprudencia, lo cual significaría la existencia de una doble vía de relación para la garantía de los Derechos Humanos mediante la materialización de la política 
pública: los sistemas de protección de Derechos Humanos, universales y regionales fijando los estándares, y los sistemas nacionales realizándolos, pero aportando a los ajustes que requieren aquellos (DULITZKY, 2007, p. 45).

Por supuesto, no se puede desconocer que gran parte de los países anglosajones tienen como una fuente importante la jurisprudencia aun para el diseño de las políticas públicas. No obstante, aun en estos sistemas jurídicos la ley era la fuente más importante de lo cotidiano, y las políticas públicas eran instrumentos bastante débiles para generar las respuestas estatales al ejercicio de derechos (LóPEZ, op. cit., p. 45-58).

Empero, en la década de los noventa ocurre un cambio estructural importante en la función del Estado. Por una parte, se perfeccionaron los métodos para la elaboración de las políticas públicas y la planificación del Estado - de acuerdo con el marco lógico del Banco Mundial, que ha servido de formato importante en todo el mundo ${ }^{11}$. Por este cambio, una de las preguntas que se hicieron los Estados era si las políticas públicas deberían ser un medio para desarrollar mecanismos concretos para el ejercicio de los derechos constitucionales.

Por esta razón, se realizó la cumbre mundial en septiembre de 2005, en la cual los estados miembros de las Naciones Unidas apoyaron de una manera decidida a los esfuerzos de la ONU por conseguir que los derechos humanos pasaran a la primera línea y al centro de toda su labor, como un compromiso colectivo que condujo a la elaboración de un "plan de acción" en el mismo año (Organización de Naciones Unidas, 2005). Allí se intentó desarrollar algunas recomendaciones para la implementación de los Derechos Humanos en los planes nacionales, especialmente, respecto del "desarrollo", que fue el eje central de la discusión en la mencionada cumbre. Posteriormente, han surgido otros documentos sobre varios temas para desarrollar esta idea original de que se integren los Derechos Humanos en las políticas nacionales. Así, por ejemplo, ocurrió con la educación, salud y el mismo desarrollo ${ }^{12}$. A continuación, voy a identificar los estándares sugeridos por estos documentos, que, a mi criterio, son la clave para leer al artículo 85 de la Constitución ya citado:

2.1 El sujeto de derechos debe ser el centro de la política pública, por lo cual deberá estar plenamente identificado, evidenciando incluso las diferencias y la diversidad específica. Al mismo tiempo, debe estar claramente determinada la responsabilidad y la autoridad obligada con determinación de las obligaciones concretas que debe prestar.

11 Cfr., Hurtado (s.f.).

12 Grupo de evaluación de Naciones Unidas (2011), Oficina del Alto Comisionado de los Derechos Humanos de Naciones Unidas (2006), Oficina del Alto Comisionado de los Derechos Humanos de Naciones Unidas (2008), Organización de Naciones Unidas (2005a) y Organización de Naciones Unidas para la Educación, la Ciencia y la Cultura (2008). 
2.2 Toda política pública debe respetar la autonomía de las personas y colectivos a quienes está dirigida, por lo cual deberá potenciar sus capacidades de entender los beneficios y responsabilidades, por tanto de ejercer los derechos. Al mismo tiempo, se debe impulsar o fortalecer las capacidades de las autoridades obligadas a no intervenir o a realizar prestaciones sociales concretas para la materialización de los Derechos Humanos.

2.3 Las políticas públicas deben estar dotadas de mecanismos de colaboración y coordinación en todas las instancias estatales y sociales, con el fin de garantizar su eficiencia e integralidad. Por esta razón, en el contexto de la Constitución de la República de Ecuador de 2008, la implementación de una política de participación social en todos los niveles de la política es una obligación (transparencia, capacitación, comunicación horizontal y vigilancia de las políticas públicas).

2.4 Una política pública con enfoque de Derechos Humanos debe fijar su horizonte en el acceso real de las personas a la justicia y no solo formal (acceso de facto y de iure), lo cual permitirá integrarla a las políticas nacionales con permanencia y un amplio espectro de impacto en la vida cotidiana de la gente.

2.5 Para la estructuración de la política pública es necesario incorporar un doble argumento: a) el argumento intrínseco, que reconoce al enfoque de derechos como el correcto sin más; y b) el argumento instrumental, que reconoce que este enfoque puede tener resultados de eficiencia y eficacia, que se funden en resultados sostenibles en el tiempo (estructurales/políticas de Estado). La aplicación de estos argumentos debe guardar relación con la posibilidad de focalizar la política en favor de las personas que se encuentren estado de indefensión, y de reproducir una visión holística, por ejemplo, en el caso de que las personas beneficiarias sean indígenas. El holismo tiene que ver, además, con la inclusión de múltiples enfoques que deben complementarse. Por ejemplo, género, diversidad sexual y étnica, interculturalidad, regionalidad, generacionalidad, niñez y adolescencia, etc.

2.6 Los derechos humanos de los instrumentos internacionales son una orientación para la elaboración de las políticas públicas nacionales (programas, mecanismos, proyectos), particularmente los principios básicos: universalidad e inalienabilidad, indivisibilidad, interdependencia e interrelación, no discriminación e igualdad, participación e inclusión, obligación de rendir cuentas y estricta legalidad.

2.7 Es importante la promoción, cohesión, integración y estabilidad sociales con el fin de que se realicen plenamente el respeto por la paz y la solución no violenta de los conflictos, y la transformación social positiva, rentable y sostenible. 


\section{PROPUESTA DE IMPLEMENTACIÓN PARA LA GARANTÍA DE LAS POLÍTICAS PÚBLICAS EN ECUADOR}

La creación de organismos, estatales y no estatales, para la defensa de los derechos humanos no es nueva. Incluso, en gran medida, el Consejo de Estado que funcionó hasta 1945 en Ecuador y el organismo que lo reemplazó, el Tribunal de Garantías Constitucionales, eran mecanismos de protección de derechos humanos, aunque con facultades reducidas. Sin embargo, el auge de los mecanismos de protección se dio en la década de 1990. En el Estado o con apoyo de este se formaron comisiones y comités de protección de los Derechos Humanos, entre los cuales se destaca la Asociación Latinoamericana de Derechos Humanos (ALDHU), que tuvo incidencia en los ochenta durante el duro régimen de León Febres-Cordero, especialmente en los casos de desaparición de los hermanos Restrepo y Consuelo Benavides ${ }^{13}$. Aquello llevó a la conformación de otras plataformas de sociedad civil: Comité Ecuménico de Derechos Humanos (CEDHU) y Asamblea Permanente de Derechos Humanos (APDH). Al mismo tiempo, en el Estado se integró finalmente la Defensoría del Pueblo (1998), y varios organismos estatales crearon oficinas especializadas para la defensa de los derechos humanos.

Así, en el antiguo Congreso Nacional (hoy Asamblea Nacional), se creó una Comisión Especializada de Derechos Humanos (1996). Y durante el actual régimen de gobierno, se fundó el Ministerio de Justicia, Derechos Humanos y Cultos, y en varios ministerios se abrieron oficinas para la defensa de los mismos como parte del mandato constitucional de 2008. También, se fortalecieron algunos planes nacionales para la protección de los derechos humanos bajo la coordinación del Ministerio de Relaciones Exteriores. Por ejemplo, el Plan Nacional contra la Tortura, el Plan Nacional contra la Violencia de Género, etc. Estos planes y programas funcionan desde la década de 1990 a través de varios consejos que estaban conformados por la sociedad civil y el Estado. Hoy estos consejos pasaron a ser parte del Estado como organismos ejecutores y por mandato de la Ley de Igualdad. Tenemos así los consejos de la igualdad, que buscan agilizar la protección de los Derechos Humanos en la actualidad. La idea de este modelo es descorporativizar los antiguos mecanismos y centralizar la rectoría de las políticas de Derechos Humanos en el Estado, no obstante la existencia de varios mecanismos de participación, control social y rendición de cuentas.

Me parece que debemos fortalecer estos consejos de la igualdad y los estándares mínimos que aquí hemos desarrollado, los cuales deben ser el primer mandato estructural para la agenda de trabajo de estos organismos. Ahora, es muy importante que se implementen políticas de participación ciudadana con el fin de que se democratice este proceso de elaboración de la política pública con enfoque en los Derechos Humanos, y se legitime la actuación conjunta entre Estado y sociedad civil para la protección integral de estos derechos de los ecuatorianos.

13 Cfr., Comisión de la Verdad (2010). 


\section{PROPUESTA DE IMPLEMENTACIÓN PARA LA POLÍTICA PENAL}

Luego, uno de los rasgos importantes de las reformas penales en América Latina ha sido el fortalecimiento de los sistemas de investigación penal y la tendencia de sustituir el sistema acusatorio por el inquisitivo. Pero, de acuerdo con los estándares de este trabajo, en materia penal, su función es limitar la punitividad del Estado (FERRAJOLI, 2000 , pp. 40-43). Esto racionaliza la política penal y legítima la operatividad penal del Estado evitando cualquier arbitrariedad, sea judicial o policial.

Genera, además, una autorreflexividad del sistema penal, pues pone en cuestión una llana aplicación de la retórica legalista y posibilita su inaplicación práctica a la luz de los derechos fundamentales. El mensaje sería de autonomía respecto de la posible agresión a los derechos consagrados dentro de las constituciones (FERRAJOLI, 2006, pp. 109-111).

Al mismo tiempo, los estándares permitirían la emergencia de un derecho penal mínimo, el cual afianza una coherente, pero a su vez no discriminada, relación entre el Estado y la sociedad civil. Se entendería que el Estado no debe abusar de las personas débiles ${ }^{14}$. También, permitiría que los jueces ocupen un papel central en el proceso penal, pues la blindaría de las simplistas lógicas de la seguridad ciudadana en su funcionamiento, toda vez que el proceso penal no gira exclusivamente alrededor de la seguridad, sino de las garantías a fin de evitar que un inocente sea condenado. Significaría, además, la consolidación de la búsqueda de la verdad y la presunción de inocencia como fines indispensables del proceso penal.

Resulta central la implementación de estos estándares en el ejercicio del derecho a la defensa, la cual no es la simple representación del procesado, sino un oficio que debe velar tanto la investigación preprocesal como procesal por la búsqueda de la verdad procesal ${ }^{15}$, evitando el aparecimiento de cualquier manifestación de arbitrariedad policial, fiscal e incluso judicial. La base del razonamiento jurídico que realiza la defensa no solo proviene de la exégesis que ofrecen las normas legales, sino además de los principios jurídicos que se desarrollan como mandatos de optimización (VILA CASADO, 2000, pp. 329-342) ${ }^{16}$, entre ellos los referidos a las garantías de la política pública, que se desarrollan a partir de los estándares que aquí he analizado.

14 Cfr. Baratta (2004), Ferrajoli (2001a, pp. 335-336) y ZafFaroni (2006, p. 228).

15 Para Julio MAIER, la verdad procesal consiste en: “...la relación de concordancia entre el pensamiento y el objeto pensado" (MAIER, 1996, pp. 841-842) y Bovino (2006).

16 Se debe esclarecer el papel que cumplen los principios y las reglas jurídicas como la base piramidal del ordenamiento jurídico kelseniano. Los primeros son la base de la política y del ordenamiento jurídico constitucional del Estado, mientras que los segundos introyectan en los jueces a convertir su jurisprudencia en una operación básicamente mecánica, pues como sostiene RoNALD DwORKIN (1995, p. 63), “...lo mejor que podríamos hacer sería echar juntos a la basura los enigmas y los conceptos y perseguir nuestros importantes objetivos sociales sin ese exceso de equipaje...". 
Finalmente, la implementación de estos estándares de la garantía de la política pública al ámbito de lo penal permitiría eliminar elementos subjetivos, mediante los cuales se violan los derechos en el día a día de la justicia penal: "alta peligrosidad" o "actitud sospechosa". Una noción de un proceso penal con garantías respecto de la defensa es vital, pues significa estar vigilante de la aplicación de los mínimos estándares del debido proceso como la presunción de inocencia, la carga acusatoria de la prueba, el real funcionamiento del contradictorio, la garantía de una igualdad de armas, la oralidad y publicidad del juicio, entre otras.

\section{CONCLUSIONES}

Tal como hemos visto, la garantía de la política pública puede ser un canal importante para la materialización de los Derechos Humanos desde el texto constitucional, toda vez que un Estado constitucional tiene un compromiso con la materialidad en su ejercicio por parte de todos en nuestro país.

Y, si bien es cierto, los estándares que he desarrollado no son los únicos, sino que constituyen un mínimo para comenzar el debate para una política coherente con nuestro Estado constitucional y la práctica diaria de los Derechos Humanos.

Su aplicación a la política penal es más que necesaria, ante la evidencia del atropello de los derechos que se da en la actuación del Estado bajo el pretexto de seguridad ciudadana o la lucha contra la delincuencia o las drogas. Además, significa el desarrollo de un poder de contención no solo a la posible violación de los derechos en el ordenamiento jurídico interno, sino, al mismo tiempo, de protección de la soberanía de nuestra política penal de las agendas de las agencias internacionales, particularmente en lo que tiene que ver con seguridad y las lógicas de dependencia del tráfico de drogas y otros delitos relacionados.

Y en este punto volvemos al problema inicial respecto de la necesidad de transformar a la política penal en una política pública. Creo que los estándares que se han sugerido en este trabajo permiten, en definitiva, transformar la política penal en una política pública. ¿Qué ventajas tendría? Muchas. Primero, permitiría establecer límites al poder punitivo desde la decisión de quienes hacen la política penal. Si se ve, en la actualidad, la política penal tiene su origen en el simple decisionismo, creando lo que los franceses llamaban "actos políticos", con lo cual aquellos quedaban fuera de cualquier control. Segundo, se daría relevancia a lo técnico y la política de largo plazo; lo cual sería distinto a lo tradicional, donde se privilegia lo coyuntural y la aceptación popular de las medidas de impacto. Y, tercero, se sometería el uso del poder punitivo a mínimos de racionalidad y proporcionalidad. Un argumento en contra, por su parte, sería la rigidez de una política penal con todos estos límites. 
En todo caso, me parece que se pierde menos si apostamos por integrar la garantía de la política pública a la política penal mediante los estándares que hemos indicado en este trabajo.

No obstante, se levantan dos barreras para las garantías de la política pública en lo penal. Por una parte, la inexistencia de un mecanismo concreto y especializado para el cumplimiento que no sean los de la garantía jurisdiccional clásica, lo cual nos lleva a plantear una discusión sobre los mecanismos de cumplimiento de las políticas públicas con enfoque de derechos humanos. Por otra parte, sin que se entorpezcan la política pública y su proceso deliberativo, deben arbitrarse formas de exigibilidad y responsabilidad de los ejecutores de las políticas públicas, pues no todo debe quedar en el ámbito de la discrecionalidad administrativa del Estado, peor solo del poder ejecutivo y mucho menos del poder punitivo. Limitar la discrecionalidad y arbitrar procedimientos de reparación se vuelve indispensable como marcos regulatorios generales dentro de los cuales deben funcionar los estándares en la política pública, particularmente penal.

Un plan nacional de desarrollo con enfoque de derechos puede ayudar mucho a la coherencia de la política y su nivel de materialización. La democratización de la política penal mediante el establecimiento de un consejo sectorial que integre a grupos de ciudadanía podría ayudar mucho a este objetivo.

Y, por la otra, lo complejo que es integrar varios enfoques a la política pública. ¿Cómo conciliar el enfoque de género y de interculturalidad? ¿Cómo no entrar en contradicciones entre el enfoque generacional y el de niñez y adolescencia? Esto nos lleva a la propuesta y estudio de canales institucionales para zanjar las diferencias y que se logre impulsar otros patrones culturales en las personas y colectivos y en los funcionarios públicos.

En todo caso, no deben descuidarse las otras formas de garantía, puesto que el Estado constitucional resulta del complejo engranaje de los poderes públicos, ciudadanía y voluntad política respecto del proyecto político de la Constitución de la República de Ecuador de 2008.

\section{BIBLIOGRAFÍA}

\section{Libros y revistas}

Abramovich, Víctor (2007). Acceso a la justicia como garantía de los derechos económicos, sociales y culturales. Estudio fijado por la Corte Interamericana de Derechos Humanos. Costa Rica: Corte Interamericana de Derechos Humanos. 
Abramovich, Víctor y Courtis, Christian (2009). Hacia la exigibilidad de los derechos económicos, sociales y culturales. Estándares internacionales y criterios de aplicación ante los tribunales locales. Instituto Interamericano de Derechos Humanos.

Baratta, Alessandro (2004). "Principios del Derecho penal mínimo (para una teoría de derechos humanos como objeto y límite de la ley penal)", en Alessandro Baratta, Criminología y sistema penal. Compilación in memoriam, Carlos Alberto Elbert (dir.), colección Memoria Criminológica n. ${ }^{\circ}$ 1. Argentina: Editorial B de F.

Bobbio, Norberto (1997). El tercero ausente. Madrid: Ediciones Cátedra.

Bovino, Alberto (2006. Problemas del derecho procesal penal contemporáneo. Buenos Aires: Editores del Puerto.

CAmargo, Pedro (1995). Manual de derechos humanos (primera edición). Colombia: Editorial LEYER.

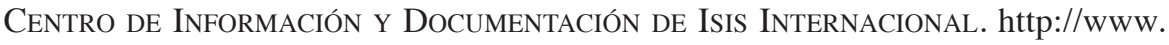
undp.org/rblac/gender/campaign-spanish/womenshumanrights.htm.

Centro por la Justicia y el Derecho InTERnacional - CeJiL (2004). Los Derechos Humanos en el Sistema Interamericano: compilación de instrumentos. Costa Rica.

Comisión Interamericana de Derechos Humanos (2002). Informe 62/02, caso 12.285, Michael Domínguez, v. Estados Unidos, 22-oct-2002.

COMISIÓN DE LA VERDAD (2010). Informe de Ecuador. Sin verdad, no hay justicia.

DulitZKy, Ariel (2007). "La aplicación de los tratados sobre derechos humanos por los tribunales locales: un estudio comparado", en Víctor Abramovich y otros, La aplicación de los tratados sobre derechos humanos en el ámbito local. La experiencia de una década. Argentina: Editorial del Puerto.

Ferrajoli, Luig (2000). “Garantías constitucionales”, en Raúl Gustavo Ferreyra y Andrés Gil Domínguez (dir.). El garantismo constitucional, Revista Argentina de Derecho Constitucional, Año I, n. ${ }^{\circ}$ 2. Buenos Aires: Ediar.

Ferrajoli, Luigi (2001). "Pasado y futuro del Estado de Derecho", en Miguel Carbonell y Rodolfo Vásquez (coord.). Estado constitucional y globalización. México: UNAM Porrúa.

FerRajoli, Luigi (2001a). Derecho y razón: teoría del garantismo penal. Madrid: Editorial Trotta. 
FERrAJoli, Luigi (2006). Garantismo. Debate sobre el derecho y la democracia, Madrid: Editorial Trotta.

GonZÁlez, NAZARIO (1998). Los derechos humanos en la historia. Barcelona: Universitat de Barcelona.

Heibner, Jorge (1993). Los Derechos Humanos. Santiago de Chile: Editorial Jurídica de Chile.

Hurtado, Osvaldo (1989). introd. "Los nuevos límites del Estado", en El problema del Estado y su reforma en América Latina. Quito: CORDES.

Hurtado, Osvaldo (1990). "El sistema político en el Ecuador”, en Ayala Mora, Enrique (ed.). Ensayos generales II: nación, estado y sistema político. Quito: Corporación Editora Nacional.

Hurtado, Osvaldo (s.f.). Gobernabilidad y reforma constitucional. Quito: Corporación Editora Nacional, Libros de bolsillo, vol. 8.

LÓPEZ, Diego (2001). El derecho de los jueces. Obligatoriedad del precedente constitucional, análisis de sentencias y líneas jurisprudenciales y teoría del Derecho judicial. Bogotá: Ediciones UNIANDES.

LÓPEZ, Diego (1993). El poder político en el Ecuador. Quito: Planeta, Letraviva.

Maier, Julio (2001). “¿Es posible todavía la realización del proceso penal en el marco de un Estado de Derecho?”, en Carlos Julio Lascano (edit.). Nuevas formulaciones en las ciencias penales: homenaje al profesor Claus Roxin. Córdoba: Facultad de Derecho y Ciencias Sociales de la Universidad Nacional de Córdoba, Editora Lerner y La Lectura Libros Jurídicos.

MAiER, Julio (1996). Derecho procesal penal. I Fundamentos. Buenos Aires: Editores del Puerto.

Medina, Cecilia (2003). La Convención Americana: teoría y jurisprudencia, Universidad de Chile.

Melish, Tara (2003). "Estableciendo la responsabilidad del Estado: el deber de respetar, el deber de garantizar y el principio de progresividad", en La protección de los Derechos Económicos, Sociales y Culturales. Serigraf.

ZafFaroni, Eugenio Raúl (2006). El enemigo en el Derecho penal. Bogotá: Grupo Editorial Jurídica Ibáñez. 


\section{Normas jurídicas}

GRUPO DE EVALUACIÓN DE NACIONES UNIDAS (2011). Integración de los derechos humanos y la igualdad de género en la evaluación - hacia una guía del UNEG. Nueva York.

Oficina del Alto Comisionado de los Derechos Humanos de Naciones Unidas (2006). Preguntas frecuentes sobre el enfoque de derechos humanos en la cooperación para el desarrollo. Nueva York y Ginebra.

Oficina del Alto Comisionado de los Derechos Humanos de Naciones Unidas (2008). Enfoque de la salud basado en los derechos humanos. Nueva York.

ORgANIZACIÓN DE NACIONES UNIDAs (2005). Un enfoque de la cooperación para el desarrollo basado en los derechos humanos. Hacia un entendimiento común entre las agencias de las Naciones Unidas. New York.

ORganización de Naciones Unidas (2005a). Declaración para un entendimiento común. El enfoque basado en los derechos humanos.

Organización de Naciones Unidas Para la Educación, la Ciencia y la Cultura (2008). Un enfoque de la educación para todos basado en los derechos humanos. Nueva York.

Sexagésimo Período de Sesiones, Asamblea General de la Organización de NACIONES UnIDAS, Resolución 60/251, 3-abr-2006. 